811.111'243:003.2

Veronika Kareva*

https://doi.org/10.18485/bells90.2020.1.ch19

South East European University

North Macedonia

Elena Spirovska**

South East European University

North Macedonia

\title{
A SYNTHESIS OF TECHNIQUE AND PROFICIENCY IN TEACHING WRITING
}

\begin{abstract}
The aim of this paper is to examine whether linguistic and composing competences are in correlation with learners' level of proficiency, that is, if more advanced learners of English are faced with the same difficulties in writing as lower proficiency learners. Twenty-eight students participated in the study: Fifteen were from the Master's program in English language teaching (ELT) and thirteen were from the same program at undergraduate level, in their fourth semester of studies. The findings highlight the most challenging areas in teaching writing among students with different proficiency. Based on the results, recommendations are offered to current and future English teachers, policy makers and educational officials for improving Teacher Training curricula.
\end{abstract}

Key words: competence, writing, proficiency, teaching

\section{Introduction}

Writing is considered to be one of the skills that students of English as a foreign/ second language (EFL/ESL) struggle with most. In fact, researchers from this field note that "achieving good composition is a complex and difficult task for both native speakers and non-native speakers of English" (Cheung 2016: 3). According to Leki (1992: 3), "no one is a 'native speaker' of writing." David Nunan, a world-renowned linguist and author of many English Language Teaching (ELT) textbooks, also notes that: "In terms of skills, producing a coherent, fluent, extended piece of writing is probably the most difficult thing there is to do in language. It is something most native speakers never master. For second language learners the challenges are enormous" (Nunan 1999: 271).

\footnotetext{
“South East European University, 335, Ilindenska, 1200 Tetovo, North Macedonia; e-mail: v.kareva@seeu. edu.mk

** South East European University, 335, Ilindenska, 1200, Tetovo, North Macedonia: e-mail: e.spirovska@ seeu.edu.mk
} 
A wide range of knowledge and experience is needed to write successfully in the native language and greater in a foreign one. Widdowson (1983, in Cheung 2016) claims that it is difficult to achieve mastery of words even if one is familiar with these words, with the task becoming more exacting when a foreign language is in question. In a study about teaching writing, Klimova (2014) concludes that students' success in writing depends on their level of English. Thus, it seems logical to assume that more proficient learners of English will encounter fewer difficulties when learning to write than lower proficiency learners. However, experience shows that advanced learners of English are also faced with difficulties in writing. What is the reason for this? Where do these difficulties come from? What is their root? How can they be overcome? Do students from the undergraduate English program have the same problems with writing as their colleagues from the Master's program who are expected to have mastered this skill and should be teaching writing? These are some of the questions that this paper seeks to answer and find possible solutions for. In order to do that, it is necessary to examine what previous research has shown about writing and its development as a skill in EFL/ESL and based on that to formulate and address the above-mentioned issues.

\section{Foreign/second language writing}

Many factors are involved and play their specific role in the development of the writing skill. The review of literature about foreign/second language writing shows that writing ability or writing competence is a serious indicator of a student's stage of learning and as such has great importance in foreign/second language teaching and research. Javadi-Safa (2006: 15) lists some special characteristics of writing which give it such importance as well as some features that make it one of the most difficult language skills. According to this author, writing is an emotional and cognitive activity. It "necessitates a confident level of writing conventions, linguistic knowledge, grammar, and vocabulary and needs thinking strategies that let the language learners express themselves proficiently in the other language." Al Fadda (2012, in Al Badi 2015) claims that the main issues in writing in the second or foreign language are: differentiating between written and spoken words and phrases, reviewing grammar and joining sentences to produce coherent paragraphs. Generating ideas is also mentioned as a barrier that hinders students to move on in their writing (Al Murshidi 2014). Kellog, (2001, in Fareed 2016) refers to the complexity of the writing skill because it is a cognitive process that tests memory, thinking ability and verbal command to successfully express ideas.

The efforts to understand writing in EFL/ESL resulted in the emergence of a number of theories in the 1980s. Hyland (2003) groups all these theories under a number of main foci important for mastering writing: language structures, text 
functions, themes or topics, creative expression, composing processes, content, genre and contexts of writing. Furthermore, with regard to learning to write, Cambell (1998) points out that whether it is at University or in high school, students are challenged to interact with written text through composing, reading, summarizing, paraphrasing, synthesizing, alluding to, reporting on, etc. Matsuda (in Kroll 2003) reflects on the complexity of the writing process in EFF/ESL and considers a number of pedagogical approaches to address it. He mentions writing as sentence level structure, writing as discourse-level structure, writing as a process and writing as language in context, all emphasizing different aspects of second/foreign language writing. Casanave (2007) writes about a list of knowledge that writing teachers and students should be familiar with: rhetorical patterns, composing conventions, the morphosyntax of the target language, its coherence-creating mechanism, written conventions, knowledge of the audience in the target culture, knowledge of the subject, etc.

The literature points out many characteristics of writing that make it a difficult discipline, requiring specific competences in order to be mastered. They can be grouped into two broad categories: linguistic and composing competence. Linguistic competence is understood in terms of Chomsky's (1965) speaker/hearer knowledge of his language and Fisher's (1984, in Nouar 2016) definition of the concept: "In the field of language learning and teaching, linguistic competence may be thought of as the learner's knowledge of the structures and vocabulary of the language and his ability to produce and comprehend well-formed sentences in the language" (para X). Linguistic competence is the mastery of the language, or language proficiency. Composing competence, on the other hand, is the knowledge about the process; "the strategies writers use to solve problems" (Krashen and Lee 2004: 10), including all the different stages of planning, drafting, revising and editing. Based on these considerations, writing competence or students' writing ability could be considered as consisting of linguistic and composing competences.

The aim of this paper is to examine whether linguistic and composing competences are in correlation with learners' level of proficiency. In other words, if more advanced learners of English are faced with the same difficulties in writing as lower proficiency learners or if their higher proficiency facilitates writing competence. Cumming (1989, in Reid 2003) investigated the relationship between composing strategies and second language proficiency and found that composing strategies were related to writing expertise (experienced, average and basic writers), but that second language proficiency was not directly related. Our assumption is that more proficient language users will be better writers than less proficient ones since their linguistic competence is higher. 


\section{Methodology}

Two instruments were used in order to elucidate the relationship between language proficiency and writing ability. Language proficiency was understood as the level of mastery of the language or language knowledge in general, while writing ability was considered to be composed of two different competences: linguistic and composing competence.

The first instrument was a questionnaire for examining students' perceptions about the issue and the second instrument were students' essays. While the questionnaire was aimed at gathering information about opinions, the analysis of the essays would provide concrete evidence about the state of their writing skills. Comparing the results from both instruments would make it possible to see the difficulties in the specific components and test the hypothesis.

Students from two different university courses and with different levels of proficiency participated in the study. The first group consisted of 13 students from the undergraduate program in English Language and Literature (BA students), attending a fourth semester course in Academic Writing and Research. According to the curriculum, they were following a skills course - Contemporary English Language 4, which according to the course description corresponded to level B2 from the Common European Framework of Reference (CEFR) (Council of Europe 2001). The second group of participants was composed of 15 students from the Master's Program in English Language Teaching, attending a course in Pedagogical Writing (MA students). Their proficiency level was not estimated by any test, but it was assumed to be at level $\mathrm{C} 1$ at least after the completion of 6 skills courses in Contemporary English in their undergraduate studies. The hypothesis was that the MA students would have fewer difficulties in writing and produce better essays because their language knowledge (proficiency) was higher.

\subsection{Analysis of the results from the questionnaire}

The questionnaire was composed of 10 items (Appendix 1), divided into two categories. Questions number 3, 4, 6 and 7 from the category of linguistic competence and questions number 4, 8, 9 and 10 from the category of composing competence. The first question was neutral and it referred to the difficulties related to writing in general, while the second question could be assigned to any of the two competencies as difficulties in expressing one's opinion may be a result of lack of vocabulary or structure (linguistic competence) or inability to generate ideas (composing competence).

Since the sample was small, data were analyzed and compared between the two groups for every question. The first item from the questionnaire, "I face difficulties with the writing assignments" did not show significant difference between the two groups 
of students (Figure 1). In both of them, half of the students experienced difficulties in writing; half of them did not.

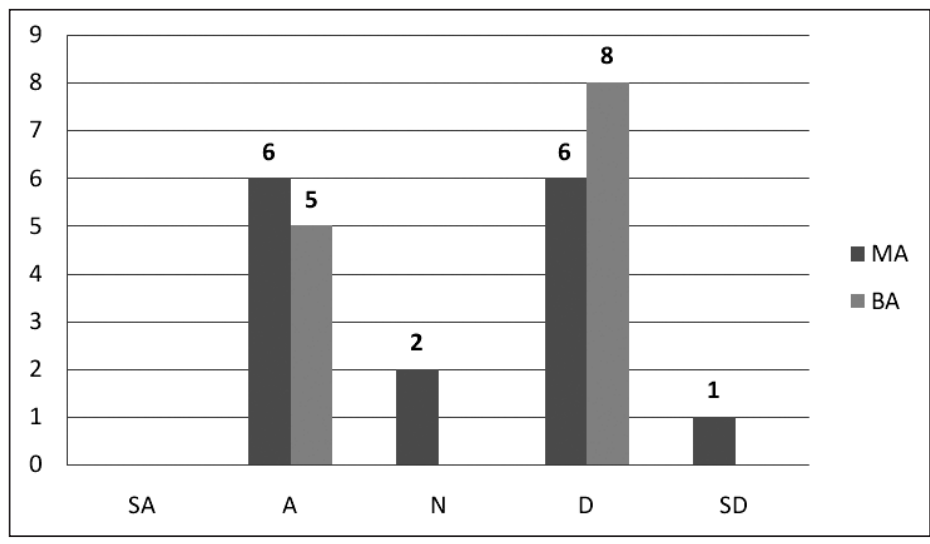

Figure 1. Difficulties with the writing assignments

The second item, "I find it difficult to express my opinion", revealed that the BA students felt more confident than the MA students, that is, the lower proficiency students had fewer issues related to expressing opinion in writing.

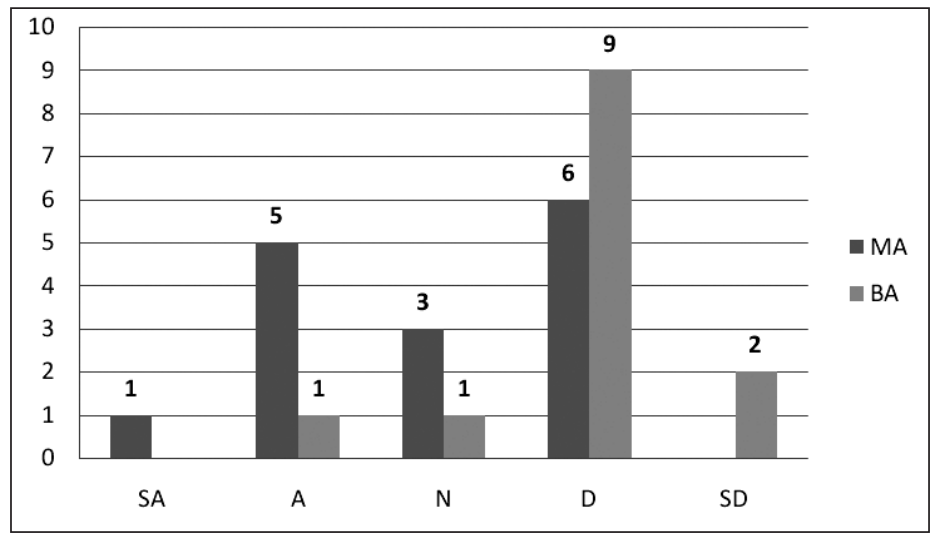

Figure 2. Difficulties with expressing opinion

Item number 3 - "My problem is the language knowledge" clearly indicated the language proficiency and the answers showed that a majority of students from both groups did not see it as an issue with their writing. 
Veronika Kareva \& Elena Spirovska

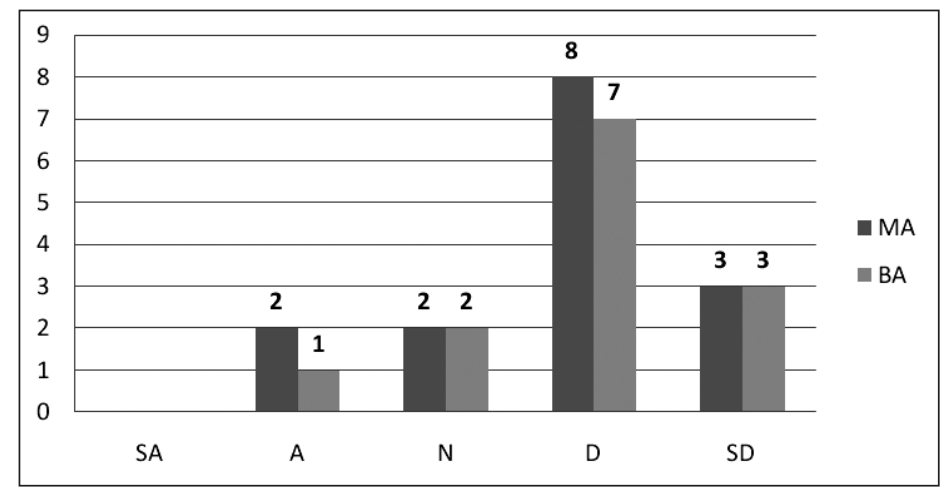

Figure 3. Problems with the language knowledge

Item number 4, "My writing needs to be more coherent" was considered to belong to the category of composing. According to the results, the MA students were more satisfied with their ability than the BA students who expressed greater concern in this segment. The results are illustrated below, in Figure 4.

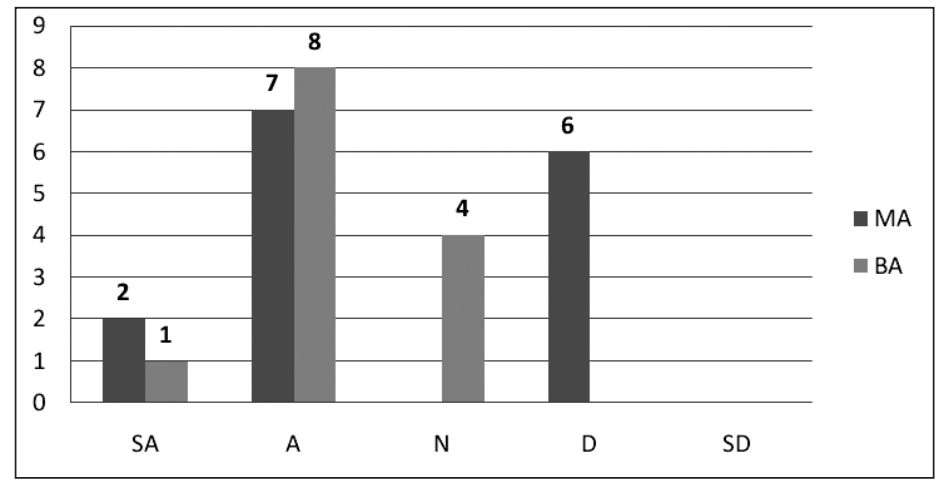

Figure 4. The need for coherence in writing

The next item, "I make a lot of mistakes in writing" was assigned to linguistic competence and the results showed that again the BA students felt less confident than the MA students. 


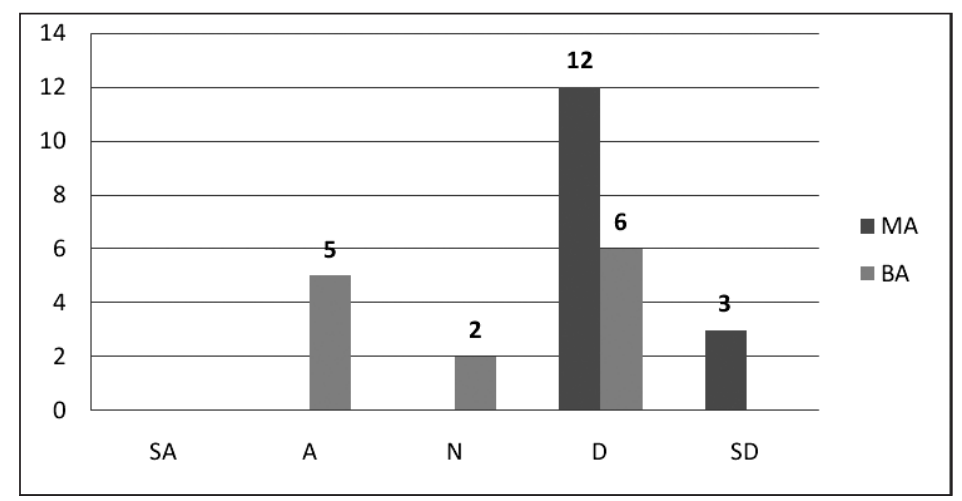

Figure 5. Making mistakes in writing

"It is difficult for me to find the right words" was the next item from the linguistic competence. The opinions about their own ability for both groups were identical. Half of the participants from each group admitted to difficulties in finding the right words and half did not. Only one examinee from the BA group was neutral. This is illustrated in Figure 6.



Figure 6. Difficulties to find the right words

Question 7 was about thinking in L1 and writing in L2. This segment was assigned to the linguistic competence: "I think in my L1 and then I write in English". Results, illustrated in Figure 7, showed that the majority of students from both groups did not face any problems in this area. 
Veronika Kareva \& Elena Spirovska

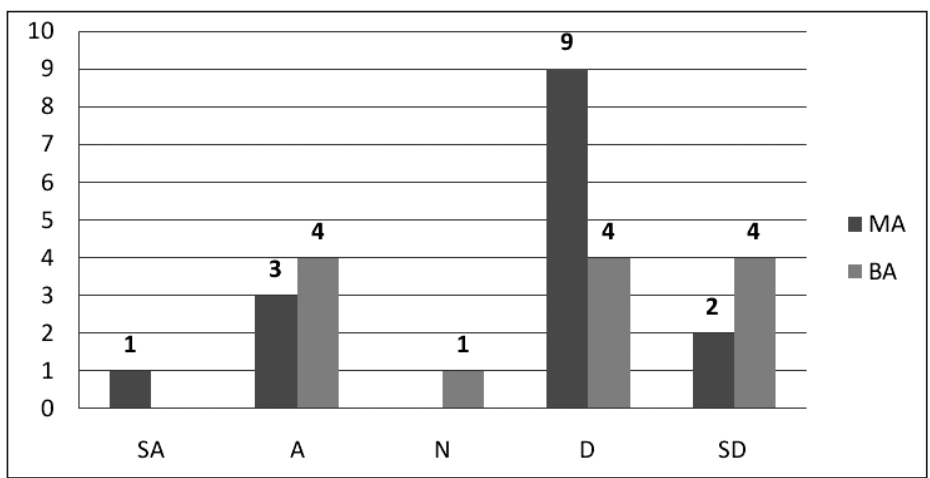

Figure 7. Thinking in L1 and then writing in L2

Item number 8 was about generating information and it referred to composing competence: "It is difficult for me to generate information". Overall, this did not seem to pose a problem for our respondents, although some MA students (almost 30\%) did express their concern (Figure 8).

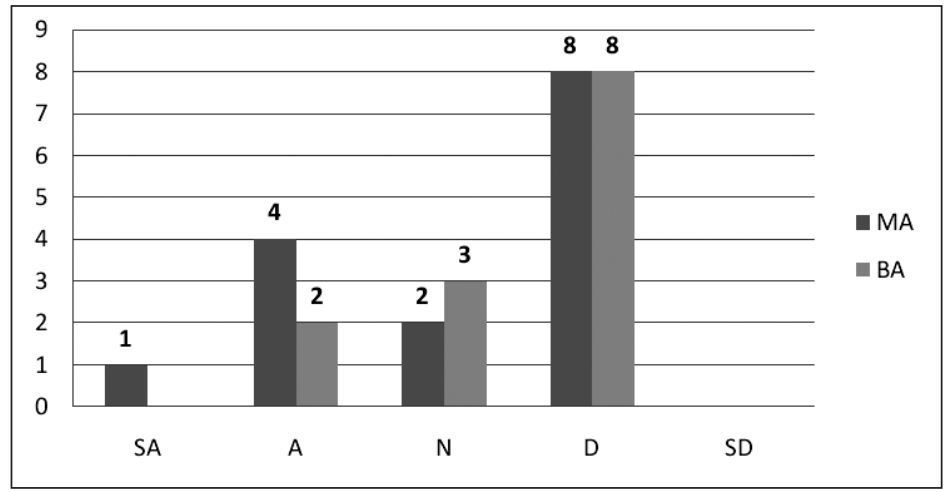

Figure 8. Difficulties with generating information

The next item was about generating ideas and it also belonged to the composing competence area (Figure 9). The results showed that the higher proficiency students (MA students) found it more difficult than the BA students (the lower proficiency ones). 


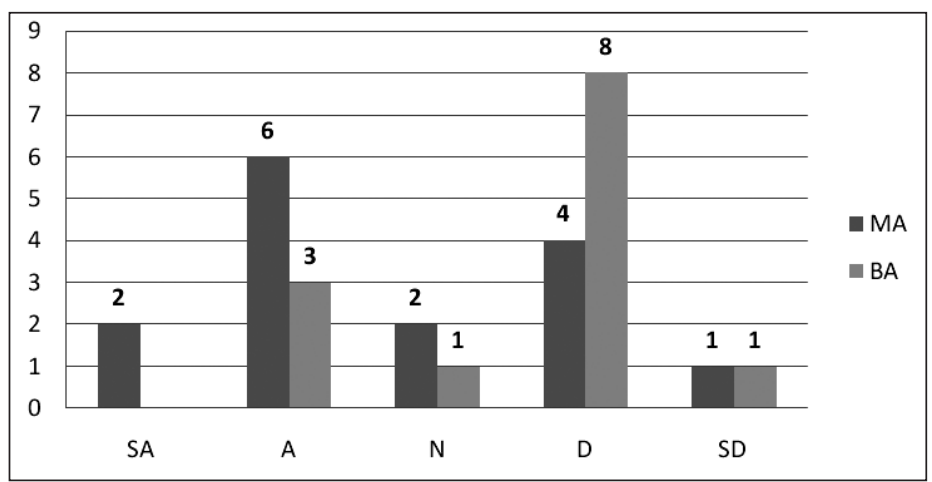

Figure 9. Getting ideas when writing

The last item also examined students' perceptions about their composing competence: "I always revise a lot when writing." Both groups were positive about this segment although the BA students somewhat less than the MA students.



Figure 10. Revising when writing

\subsection{Analysis of the essays}

The two groups were given different topics for writing a persuasive essay. Prior to writing the essay, the undergraduate group had been given instruction and some practice with writing essays that persuade, while the Master's group wrote the essays as an activity within the module on giving feedback on students' writing. Both groups were motivated to do their best and compose good essays, because the undergraduate students received points for their final grades, while the Master's students were evaluated by their peers anonymously. 
Both groups wrote essays according to the same instructions about the type, length and structure. The BA group could choose from a wide range of topics, while the MA students were all given the same topic. In both cases it was a class activity. Apart from a few cases, the essays from the BA students were generally shorter. All students tried to organize their essays logically and used transition words but most of the students had difficulties with coherence.

The MA students wrote longer essays. They were all well informed about the topic they wrote (inclusive education) and had many ideas about it. However, their writing was more descriptive than persuasive (this is a general perception for the group as a whole). The biggest issue again was the lack of ability to write coherently. The focus of the essays would not always be clearly stated and consequently, the rest of the essay did not seem well organized.

\section{Conclusions}

The main goal of the study was to see if linguistic and composing competences as the main constituent components of writing competence were in correlation with learners' level of proficiency, i.e. if more advanced learners of English experienced fewer difficulties in writing than lower proficiency learners.

There was no difference in the students' perceptions about the difficulties with their writing skills between the higher and lower proficiency students although half of the participants from both groups admitted they had issues related to writing. Surprisingly, the more proficient (MA) students found it more difficult to express their opinion than the lower proficiency (BA) students. The language knowledge was not seen as an issue by either of the examined groups of students while achieving coherence in writing was more problematic for the lower proficiency students. They were the ones who said they made more mistakes while writing. There was no difference in the perceptions between the two groups about finding the right words and thinking in L1 before writing in L2. The higher proficiency students had more difficulties in generating information and getting ideas whereas both groups claimed that they revised their pieces of writing.

Grouping and comparing the answers from the higher and lower proficiency students according to the two categories that were examined (linguistic and composing) showed that the higher proficiency students found it more problematic to express their opinions, generate information and get ideas than the lower proficiency students. All these components were parts of the composing competence. The only segment from the composing competence where the lower proficiency students felt less confident was coherence and the only segment from the linguistic competence where they struggled more was making mistakes. 
These results clearly showed that higher proficiency and language knowledge did not necessarily ensure good writing ability. The hypothesis that language proficiency was in correlation with linguistic and composing competences as the two parts of the writing competence, was not confirmed.

Analysis of the essays reconfirmed the findings from the questionnaire. While the higher proficiency students wrote longer essays, the lower proficiency students paid more attention to essay organization and structure. In general, they wrote shorter essays (with a few exceptions), but they would more clearly state the problem, provide evidence and develop the main idea with examples and facts. The impression was that they had really mastered the functional approach to writing (Hyland 2003). Compared to them, the higher proficiency students wrote in a more descriptive way, without paying much attention to writing technique.

The small sample was one of the limitations of the study; the specific setting was another one. The lower proficiency students were attending a writing course at the time when the research was being conducted and the material they studied influenced their answers and the essays they wrote. Yet, it was obvious that they produced better structured essays. What is more, the lower proficiency students especially paid attention to creating coherence between the different parts despite the fact that in the questionnaire they had claimed to have more difficulties with coherence than the higher proficiency students. This discrepancy between the actual performance and the perceptions about the ability to create coherent writing pieces might be a result of awareness and self reflection on the part of the lower proficiency students which on the other hand was lacking with the other group of students. The higher proficiency (MA) students might have felt more confident with writing because of their mastery of the language, but in practice it did not seem to help them much with their writing tasks. Both groups of students experienced difficulties with writing.

The general conclusion is that writing as a language skill, or writing competence is not related to the language knowledge. The very fact that one can speak a language well does not mean that he/she can write in that language in a good way. Speaking and writing skills differ a lot despite the claim that written language emerged from spoken language (Nunan 1999). Writing is more than "talk written down" (Nunan 1999: 275). The writing skill is a complex matter and it requires more than knowing the language. It entails drafting and redrafting, evaluating one's own writing, determining one's own reason or purpose for developing a paper in a certain direction. This is true for the mother tongue and the same refers to writing in the second language. Writing can be mastered through practicing technique. Relying on the language knowledge i.e. proficiency is not sufficient and does not automatically mean good writing. Therefore, it is not strange that writing is the last language skill acquired even in the mother tongue and the same challenges face second language learners. 
These conclusions are based on findings from research conducted with fluent students. It would be beneficial to check if the same would be valid with different proficiency students from lower levels. The writing task in that case would be a paragraph instead of an essay. However, the thinking processes and the writing technique necessary to complete the task successfully is the same with both tasks. A factor that could make a difference with lower proficiency students is the inference of the Language Threshold Hypothesis (Grabe 2003, in Kroll 2012), according to which the transfer from the mother tongue is not possible unless certain proficiency in the target language is achieved. This means that students with low proficiency would not be able to apply the techniques they have learnt in their L1 to the target language writing and this might influence the final result. Nonetheless, at least when the local languages (Macedonian and Albanian) are the L1 and especially at state schools, there is hardly anything to transfer to the target language as very little attention is paid to teaching writing in the L1s.

\section{Implications for teaching}

Understanding the complexity of writing is critical in teaching writing. Teachers need to adopt writing pedagogy that will help students become trained in the thinking processes that underlie the writing competence. What teachers of second language writing should do is well summarized by Campbell (1998: 3): "I wish my teachers had challenged me with more reasons to write, helping me determine what I wanted papers to accomplish. I wish my teachers had pushed me to peek at the complexity of the range of directions and attitudes I could take in my writing, and then I wish they had guided me in strategies for putting those attitudes and ideas into print."

Teachers of second language writing should consider and reflect upon the different approaches to teaching writing and be able to take the appropriate stand with their students. At the same time, they need to "teach students the socio-cognitive approach to writing, which takes into consideration readers' expectations, sociocultural contexts, and thinking processes involved in planning, organizing, and writing/ revising the essays" (Ling-Cheung 2016: 17). This approach must be used from the very beginning and with low proficiency students instead of waiting for a certain level of proficiency to be achieved and then working on shaping the thinking processes. It would be even more useful for such an approach to be practiced while writing in L1 and then the same technique could be transferred to L2. Only after making sure that they have done their best to teach students how to focus the thinking processes needed before and during the writing tasks, can teachers deal with some of the usual controversies related to L1 and L2 including: 
Questions about the incompatibility of fluency and accuracy, the contrastive rhetoric debate, the process-product debate, ways to assess improvement, the purpose and value of different kinds of feedback and error correction on writing, the argument about the value of explicit teaching of genres versus situated practice, issues of audience and plagiarism, etc. (Casanave 2007: 1)

First of all, students need to be encouraged and motivated to write more. They should not be afraid of the written tasks. Teachers have to use every occasion for training students to expand their thinking beyond the simple ways of conveying meaning and basic communication. Lower proficiency students can start with putting down their ideas even if they are in a form of words denoting notions as a result of association and brainstorming and then connecting them in logical sentences. Higher proficiency students have to learn to formulate their opinions and not over generalize things. Teachers should guide them in these steps by constant challenging, provocation, inspiration, providing examples, giving models. It is a lot of work, but nothing is more rewarding for a teacher than seeing a good piece of writing, demonstrating an autonomous way of thinking and knowing that you have contributed to it.

\section{References}

Al Badi, I. A. H. (2015). Academic Writing difficulties of ESL learners. International academic conference Proceedings, Barcelona, Spain, 2015. (2 September 2019) $<$ https://www.westeastinstitute.com/wp-content/uploads/2015/02/Ibtisam-AliHassan-Al-Badi-full-Paper.pdf>.

Al Murshidi, G. (2014). UAE university male students' interests impact on reading and performance and improvement. English Language Teaching, 7(9), 57-63.

Cheung, Y. L. (2016). Teaching Writing. In: W. A. Renandya and H. P. Widodo (eds.), English Language Teaching Today: Building a Closer Link Between Theory and Practice, New York, NY: Springer International. (31 August 2019) <https:// www.academia.edu/23725735/Teaching_Writing>.

Casanave, C. P. (2007). Controversies in Second Language Writing. Ann Arbor: The University of Michigan Press.

Chomsky, N. (1965). Aspects of the theory of syntax. Cambridge, Mass: MIT press.

Council of Europe (2001). Common European Framework of Reference for Languages: Learning, Teaching, Assessment. (4 September 2019) <https:// rm.coe.int/1680459f97>. 
Fareed, M. (2016). ESL Learners' Writing Skills: Problems, Factors and Suggestions. Journal of Education and Social Sciences, 4(2). (2 September 2019) < https:// www.researchgate.net/publication/311669829_ESL_Learners'_Writing Skills_Problems_Factors_and_Suggestions>.

Hyland, K. (2003). Second Language Writing. Cambridge: Cambridge University Press.

Javadi-Safa, A. (2018). A Brief Overview of Key Issues in Second Language Writing Teaching Research. International Journal of Education \& Literacy Studies, 6/2. (1 September 2019) <https://www.researchgate.net/publication/325804137_A_ Brief_Overview_of_Key_Issues_in_Second_Language_Writing_Teaching and_Research>.

Klimova, B. (2014). Approaches to the teaching of writing skills. Procedia - Social and Behavioral Sciences, 112, 147-151. (2 September 2019) <https://www. sciencedirect.com/science/article/pii/S1877042814011665>.

Krashen, S. and S. Lee (2004). Competence in Foreign Language Writing: Progress and Lacunae. On Cue, 12, 2. (3 September 2019) <http://www-o.ntust.edu. tw/ syying.lee/publications/Competence_in_foreign.pdf $>$.

Kroll, B. (2003). Exploring the Dynamics of Second Language Writing. Cambridge: Cambridge University Press.

Lehman, C. (2007). Linguistic Competence. Folia Linguistica, 41, 223-278. (31 August 2019) <https://www.researchgate.net/publication/249929097_Linguistic_ competence_Theory_and_empiry>.

Leki, I. (1992). Understanding ESL Writers: A guide for teachers. Portsmouth, New Hampshire: Cook Publishers.

Ling_Cheung,Y.(2016). Teaching Writing. Springer International.(07 November2019) $<$ https://www.academia.edu/23725735/Teaching_Writing $>$.

Nouar, Y. (2016). Linguistic competence, communicative competence, pragmatic competence and their implications for foreign language teaching and testing. (3 September 2019) <http://fac.umc.edu.dz/fll/images/expressions/YasminaNOUAR.pdf>.

Nunan, D. (1999). Second Language Teaching and Learning. Boston, Massachusetts: Heinle and Heinle Publishers.

Reid, J. M. (1993). Teaching ESL Writing. Englewood Cliffs, N. J: Regents/Prentice Hall. 


\section{Appendix 1}

\section{STUDENTS' QUESTIONNAIRE}

You are: (circle one option) MA student BA student

Instructions: Tick one of the answers - Strongly agree (SA), Agree (A) No opinion (N), Disagree (D); Strongly Disagree (SD) next to the statement that best expresses your own opinion about writing in English.

\begin{tabular}{|l|l|l|l|l|l|l|}
\hline \multicolumn{2}{|l|}{} & SA & A & N & D & SD \\
\hline 1 & I face difficulties with the writing assignments. & & & & & \\
\hline 2 & I find it difficult to express my opinion. & & & & & \\
\hline 3 & My problem is the language knowledge. & & & & & \\
\hline 4 & My writing needs to be more coherent. & & & & & \\
\hline 5 & I make a lot of mistakes in writing. & & & & & \\
\hline 6 & It is difficult for me to find the right words. & & & & & \\
\hline 7 & I think in my L1 and then I write in English. & & & & & \\
\hline 8 & It is difficult for me to generate information. & & & & & \\
\hline 9 & I find it difficult to get ideas when writing. & & & & & \\
\hline 10 & I always revise a lot when writing. & & & & & \\
\hline
\end{tabular}

